\title{
Oculosporidiosis Presenting as a Conjunctival Polyp in North India
}

\author{
Parveen Rana, Satyavir Kishor Mathur, Manisha Nada, Sonia Chhabra \\ Department of Pathology, Post Graduate Institute of Medical Sciences, Rohtak, India
}

\begin{abstract}
Rhinosporodiosis, caused by Rhinosporidium seeberi, is a chronic localized granulomatous disease of the mucus membrane. This report is of a patient with oculosporidiosis involving the conjunctiva with a clinical presentation in the form of polyp. The patient was treated by surgical excision, and the resected tissue was submitted for histopathological examination, which confirmed the diagnosis.
\end{abstract}

Key words: Conjunctiva, Mucus membrane, Polyps, Rhinosporodiosis, Rhinosporidium

Asian J Ophthalmol. 2011;13:27-8.

\section{Introduction}

Rhinosporidiosis is a granulomatous disease of the mucus membrane caused by Rhinosporidium seeberi. $R$ seeberi is an organism of uncertain taxonomic position, which is not a classic fungus but an aquatic protistan parasite belonging to the class Mesomycetozoea. ${ }^{1} R$ seeberi occurs worldwide, but is endemic in Africa and Asia and is most frequent in the southern and eastern parts of India. The usual sites of this infection are the nose and the nasopharynx, but it may infect all the other mucus membranes and the skin. Involvement of the eye and its related structures is called oculosporidiosis. Most frequently, the lacrimal sac is affected by extension from the nasal mucosa. Conjunctival involvement is a primary infection. ${ }^{2-4}$

\section{Case Report}

A healthy 22-year-old man presented to the Ophthalmic Outpatient Department, Post Graduate Institute of Medical Sciences, Rohtak, India, in $\mathbf{2 0 0 9}$ with a small polypoidal growth in the superior palpebral conjunctiva near the medial canthus of the left eye (Figure 1). The polyp was soft and pink, with a few grey-white spots on the surface. All haematological investigations and systemic examination were normal. Excisional biopsy of the polypoidal growth was performed. The conjunctival membrane healed well after surgery and required no further treatment.

Gross pathological examination of the biopsy specimen showed polypoidal tissue with flakes of membrane attached. Light microscopy examination of the excised tissue showed multiple

Correspondence: Dr Parveen Rana, Department of Pathology, PGIMS, Rohtak 124001, Haryana, India.

Tel: (91 98) 9621 1426;

E-mail: zskundu2003@rediffmail.com
Figure 1. A small poypoidal growth on the palpebral conjunctiva.

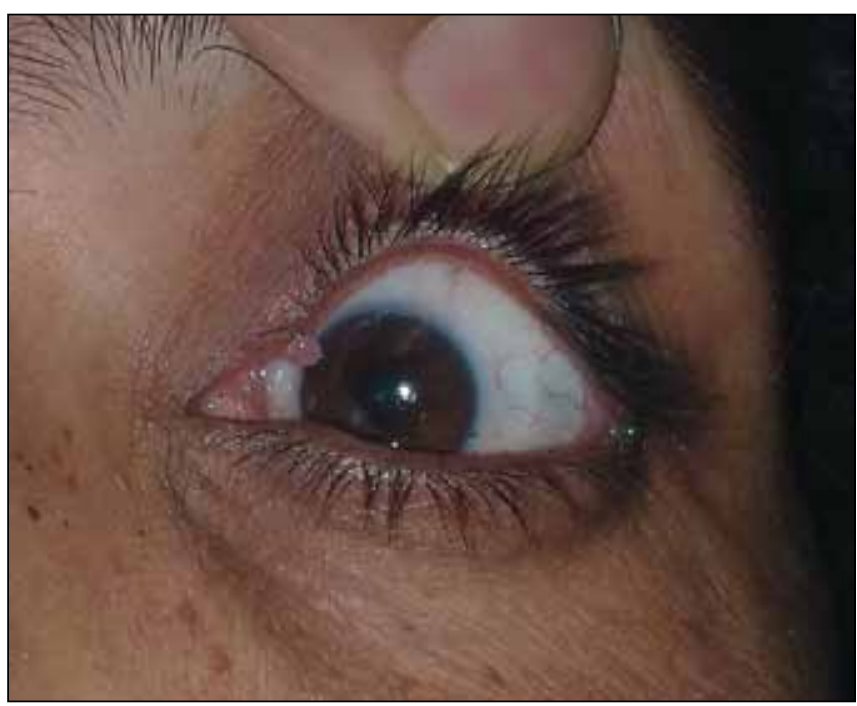

sporangias, 100 to $200 \mu \mathrm{m}$ in diameter, at various stages of maturation and containing numerous endospores in the sporangium and stroma (Figure 2). The sporangia were double-walled cysts. The cysts contained many vacuoles and eosinophilic granular material (Figure 3).

\section{Discussion}

Rhinosporidiosis is endemic in South Asia notably in the southern and eastern parts of India and Sri Lanka. The mode of transmission of oculosporidiosis is controversial. It is believed to be dust- and air-borne and is a disease of the summer months in contrast to the nasal infection that is water-borne and increasingly encountered in the winter months. ${ }^{5}$

Rhinosporidiosis is an inflammatory disease characterised by hyperplastic polypoid lesions of the nasal cavity and, rarely, of other 
Figure 2. Conjunctival epithelium showing sporangia (haematoxylin and eosin stain; original magnification, $x$ 100).

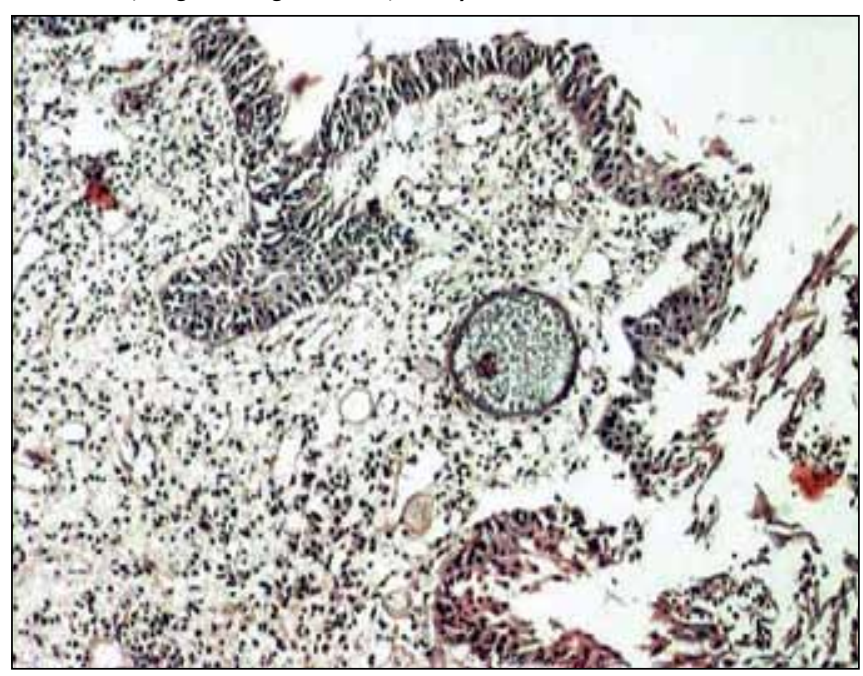

Figure 3. Sporangium containing numerous endospores (haematoxylin and eosin stain; original magnification, $x$ 400).

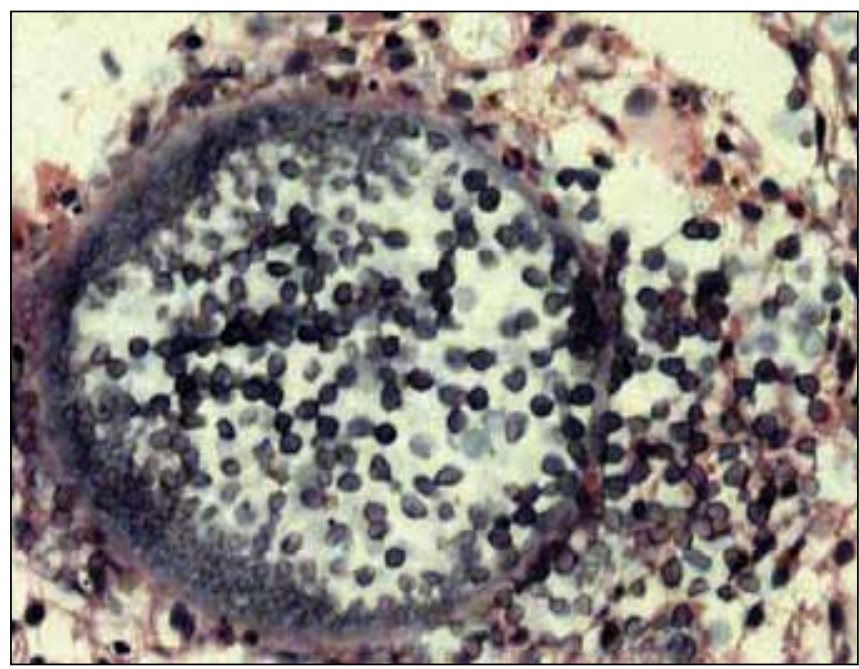

mucous membranes. ${ }^{6,7}$ Involvement of the conjunctival membrane is relatively rare. The ratio of nose to eye infection is $4.6: 1$. The typical lesion of rhinosporidiosis is fleshy, vascular, dark red, polypoidal, and granulomatous with greyish white dots (spherules) representing fungal sporangia present on the surface..$^{8,9}$ The granulomatous masses can grow to resemble mucosal tumours. Epidemiological studies have shown that conjunctival rhinosporidiosis has a predilection for agricultural workers, and contact with contaminated soil may be a causative factor. ${ }^{10}$
Light and electron microscopic studies have provided most information on the organism. A young trophozoite undergoes nuclear division until it contains over 4000 nuclei. The inner layer of the trophozoite's membrane differentiates as a mature sporangium containing thousands of endospores.

The treatment of rhinosporidiosis consists of meticulous surgical excision. Recurrences are rare and can be minimised by cauterising the base of the lesion with $2 \%$ silver nitrate solution or cryopexy can be applied. However, recurrence is due to spillage of endospores on the adjacent mucosa. Medical therapy is controversial. Some authors have proposed dapsone $100 \mathrm{mg}$ once or twice daily for 3 to 6 months to prevent recurrence. Dapsone acts by arresting the maturation of sporangia, accelerating degenerative change, and promoting fibrosis in the stroma. ${ }^{11}$ If left untreated, long-standing disease may cause secondary bacterial infections and thickening of the eyelid (ptylosis).

In conclusion, oculosporidiosis is a condition that clinicians and pathologists should keep in mind when managing patients in countries where the disease is endemic and those presenting with conjunctival masses. ${ }^{12}$

\section{References}

1. Arseculeratne SN. Recent advances in rhinosporidiosis and Rhinosporidium seeberi. Indian J Med Microbiol. 2002;20:119-31.

2. De Doncker RM, De Keizer RJ, Oasterhuis JA, Maes A. Scleral melting in a patient with conjunctival rhinopsoridiosis. $\mathrm{Br} \mathrm{J}$ Ophthalmol. 1990;74;635-7.

3. Neumayr TG. Bilateral rhinosporidiosis of the conjunctiva. Arch Ophthalmol. 1964;71:379-81.

4. Jimenez JF, Young DE, Hough AJ. Rhinosporidiosis. A report of two cases from Arkansas. Am J Clin Pathol. 1984;82:611-5.

5. Sood NN, Rao SN. Rhinosporidium granuloma of the conjunctiva. J Pediatr Ophthalmol. 1969;6:142-4.

6. Harissi-Dagher M, Robillard N, Corriveau C, Mabon M, Allaire GS. Histopathologically confirmed ocular rhinosporidiosis in two Canadians. Can J Ophthalmol. 2006;41:227-9.

7. Rosai J. Respiratory tract. In: Rosai J, editor. Rosai and Ackermann's surgical pathology. 9th ed. Missouri: Mosby; 2004. p 307.

8. Sharma KD, Shrivastav JB, Agarwal S. Ocular rhinosporidiosis simulating a tumour. Br J Ophthalmol. 1958;42:572-4.

9. Karunaratne WA. Rhinosporidiosis in man. London: Athlone Press, University of London; 1964.

10. Owor R, Wamukota WM. Rhinosporidiosis in Uganda. A review of 51 cases. East Afr Med J. 1978;55:582-6.

11. Vijaikumar M, Thappa DM, Karthikeyan $\mathrm{K}$, Jayanthi S. A verrucous lesion of the palm. Postgrad Med J. 2002;78:302,305-6.

12. Morelli L, Polce M, Piscioli F, et al. Human nasal rhinosporidiosis: an Italian case report. Diagn Pathol 2006;1:25. 